\title{
Hematemesis in a 67 Year Old Male
}

\section{Parastoo Jangouk', Victor Chedid ${ }^{1 *}$ and Jana G Hashash ${ }^{2}$}

${ }^{1}$ Department of Internal Medicine, University of Pittsburgh Medical Center, USA

${ }^{2}$ Division of Gastroenterology, Hepatology and Nutrition, University of Pittsburgh Medical Center, USA

Keywords: GI bleeding; Aortoenteric fistula

\section{Introduction}

Aortoenteric Fistula (AEF) is a rare and life threatening condition that has been challenging to diagnose and manage [1]. Early diagnosis and treatment is important to prevent fatal outcomes. While multiple diagnostic modalities have been used to help diagnose AEF, including upper endoscopy, aortogram, and Computed Tomography (CT) angiography; a high clinical suspicion and history remain of utmost importance for the diagnosis. Esophago Gastroduodeno Scopy (EGD) and CT scans are the most helpful diagnostic studies [2]. Mortality rates remain as high as 33\%, despite advancement in surgical repair [2].

\section{Case Report}

We present the case of a 67 -year-old male with a history of abdominal aortic aneurysm (AAA), repaired 11 years ago, who presented to our institution after an episode of hematemesis. The patient has a medical history significant for coronary artery disease (CAD), hypertension, and dyslipidemia. On revision of his past medical history, the patient had an open repair of an aortoiliac AAA 11 years ago. One year prior to presentation, the patient underwent a coronary artery bypass grafting (CABG) for CAD and has been maintained on Aspirin. At that time the patient developed a deep vein thrombosis (DVT) and has been maintained on warfarin since then.

On admission, the patient was hemodynamically stable with a blood pressure of 120/75 $\mathrm{mmHg}$ and a pulse rate of 80 beats-per-minute. The patient's physical examination was otherwise unremarkable except for a digital rectal exam that revealed melena. Admission blood work showed hemoglobin of $12.8 \mathrm{~g} / \mathrm{dL}$, a blood urea nitrogen level of 20 $\mathrm{mg} / \mathrm{dL}$ (upper limit of normal $26 \mathrm{mg} / \mathrm{dL}$ ), creatinine $0.7 \mathrm{mg} / \mathrm{dL}$ and an INR of 1.1. An upper endoscopy was performed to further evaluate the etiology of hematemesis. The esophagus and the stomach appeared normal. There was an abnormality noted in the second/third part of the duodenum just distal to the papilla as displayed in Figure 1.

The non-bleeding lesion seen in the second/third portion of the duodenum on endoscopy was highly suspicious for an Aorto Enteric Fistula (AEF). At time of the upper endoscopy, there was no active bleeding. After endoscopy, a CT angiogram was performed and this

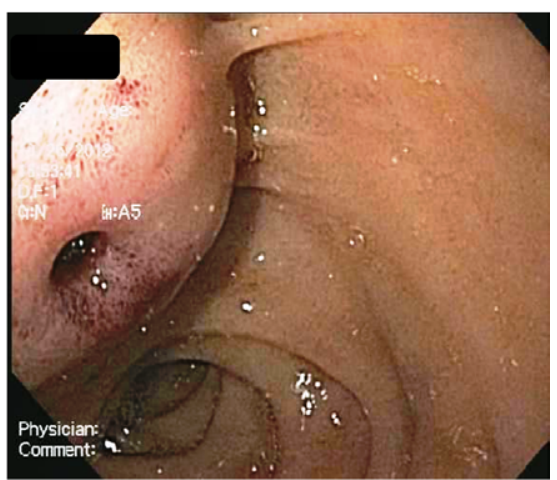

Figure 1: Abnormality noted in the second/third part of the duodenum just distal to the papilla. revealed a large aortic pseudoaneurysm abutting the second/third portion of the duodenum concerning for an AEF. Following CT angiography and endoscopy, the patient underwent AEF repair and debridement of the duodenal perforation. The patient had a prolonged hospitalization after repair of the AEF complicated by VRE bacteremia. After recovery, he did very well and has been regularly followed up in the Vascular Clinic with no post-operative complications.

\section{Discussion}

AEF is an open link between the aorta and the gastrointestinal tract. Primary AEF are a spontaneous connection arising from atherosclerotic aortic aneurysms [3]. While secondary AEF occur in the setting prior abdominal aortic vascular grafts [3]. These have a postoperative incidence of $0.5-2.3 \%$ [3]. Primary AEF is a rare entity and has an incidence of 0.07 per cent of the general population [4]. It is reported that $1 \%$ of acute aneurysms have an associated PEF [5]. Our patient with a history of AAA repair has a secondary AEF. Most common sites for AEF are the third and fourth portions of the duodenum, occurring in $60 \%$ of cases [1]. While less common locations include the jejunum, stomach, and any segment of the colon, each accounting for less than $5 \%$ of cases [1]. As we saw in our patient, the fistula was apparent on EGD in the third part of the duodenum. A classical triad of upper gastrointestinal bleeding, abdominal pain and pulsatile mass has been historically described $[5,6]$ More recent studies showed that $11 \%$ of patients had the triad, while $94 \%$ had signs of GI bleed [4]. As described in the study by Saers et al., most of these patients have a sentinel hemorrhage which is minor, followed by a massive fatal bleed [4]. Interestingly our patient was hemodynamically stable and did not have the classical triad symptoms of AEF. Although rare, bleeding AEF is associated with high mortality if undiagnosed [2]. A high index of suspicion is needed in all patients with massive or intermittent upper gastrointestinal bleeding and history of aortic aneurysm or prosthetic vascular graft. Initial diagnostic modality is upper endoscopy, but the best diagnostic modality is abdominal CT [1]. Most common CT finding is an ectopic gas within or adjacent to the aortic lumen [1]. This sign is not specific, especially in the early post-op period when this is a normal finding [1]. At times, a direct gas tract can be identified from the bowel loop to the aorta. Endoscopy is important to rule out other causes of gastrointestinal bleeding. Immediate surgical repair of the aortic aneurysm and fistula is the standard treatment regardless of the cause [7].

*Corresponding author: Victor Chedid, Department of Internal Medicine
University of Pittsburgh Medical Center, USA, Tel: 412-648-9115; Fax: 412-648 9378; E-mail: chedidv@upmc.edu

Received June 29, 2014; Accepted September 15, 2014; Published September 23, 2014

Citation: Jangouk P, Chedid V, Hashash JG (2014) Hematemesis in a 67 Year Old Male. J Clin Case Rep 4: 419. doi:10.4172/2165-7920.1000419

Copyright: (c) 2014 Jangouk $P$, et al. This is an open-access article distributed under the terms of the Creative Commons Attribution License, which permits unrestricted use, distribution, and reproduction in any medium, provided the original author and source are credited. 


\section{Conclusion}

In our patient, suspicion for an AEF was high, given his history of AAA repair and the presence of a fistulous tract in the duodenum on endoscopy. It is important to maintain a high suspicion in patients with a similar history, as the consequences can be fatal if not treated swiftly and appropriately. Our patient's course was complicated by VRE bacteremia. In addition to surgery, antibiotics prior to surgery and post-operatively is prudent in the treatment of these patients. Gram-negative as well as gram positive coverage is indicated to cover for enteric bacteria. Antibiotic duration is directed according to intraoperative blood cultures. If negative, one should complete a one-week course, while if positive; antibiotics should be kept for 4-6 weeks [4].

\section{References}

1. Raman SP, Kamaya A, Federle M, Fishman EK (2013) Aortoenteric fistulas: spectrum of CT findings. Abdom Imaging 38: 367-375.
2. Busuttil SJ, Goldstone J (2001) Diagnosis and management of aortoenteric fistulas. Semin Vasc Surg 14: 302-311.

3. Lemos DW, Raffetto JD, Moore TC, Menzoian JO (2003) Primary aortoduodenal fistula: a case report and review of the literature. J Vasc Surg 37: 686-689.

4. Saers SJ, Scheltinga MR (2005) Primary aortoenteric fistula. Br J Surg 92: 143-152.

5. Voorhoeve R, Moll FL, de Letter JA, Bast TJ, Wester JP, et al. (1996) Primary aortoenteric fistula: report of eight new cases and review of the literature. Ann Vasc Surg 10: 40-48.

6. Korkut AK, Arpinar E, Yasar T, Guney D (2000) Primary aortoduodenal fistula complicated by abdominal aortic aneurysm. J Cardiovasc Surg (Torino) 41 : 113-115.

7. Kakkos SK, Antoniadis PN, Klonaris CN, Papazoglou KO, Giannoukas AD, et al. (2011) Open or endovascular repair of aortoenteric fistulas? A multicentre comparative study. Eur J Vasc Endovasc Surg 41: 625-634. 